\title{
Genome-wide gene expression profiling of human mast cells stimulated by IgE or Fc\&RI-aggregation reveals a complex network of genes involved in inflammatory responses
}

\author{
Manikandan Jayapal ${ }^{1}$, Hwee Kee Tay ${ }^{1}$, Renji Reghunathan ${ }^{1}$, Liang Zhi ${ }^{1}$, \\ Kah Kiong Chow ${ }^{2}$, Mary Rauff ${ }^{3}$ and Alirio J Melendez*1
}

Address: ${ }^{1}$ Department of Physiology, National University of Singapore, Singapore, ${ }^{2}$ Department of Obstetrics \& Gynecology, Gleneagles Medical Centre, Singapore and ${ }^{3}$ Department of Obstetrics \& Gynecology, National University of Singapore, Singapore

Email: Manikandan Jayapal - phsjm@nus.edu.sg; Hwee Kee Tay -g0202545@nus.edu.sg; Renji Reghunathan - phsrr@nus.edu.sg; Liang Zhi - phczl@nus.edu.sg; Kah Kiong Chow - g0500896@nus.edu.sg; Mary Rauff - obgmr@nus.edu.sg;

Alirio J Melendez* - phsmraj@nus.edu.sg

* Corresponding author

BMC Genomics 2006, 7:210 doi:10.1186/147|-2164-7-210

This article is available from: http://www.biomedcentral.com/I47I-2164/7/210

(C) 2006 Jayapal et al; licensee BioMed Central Ltd.

This is an Open Access article distributed under the terms of the Creative Commons Attribution License (http://creativecommons.org/licenses/by/2.0), which permits unrestricted use, distribution, and reproduction in any medium, provided the original work is properly cited.

\begin{abstract}
Background: Mast cells are well established effectors of IgE-triggered allergic reactions and immune responses to parasitic infections. Recent studies indicate that mast cells may play roles in adaptive and innate immunity, suggesting an innovative view of the regulation of immune responses. Here, we profiled the transcriptome of human mast cells sensitized with IgE alone, or stimulated by $\mathrm{F} c \varepsilon \mathrm{RI}$ aggregation.
\end{abstract}

Results: Our data show that among 8,793 genes examined, 559 genes are differentially regulated in stimulated mast cells when compared with resting/unstimulated mast cells. The major functional categories of upregulated genes include cytokines, chemokines, and other genes involved in innate and adaptive immune-responses. We observed the increased expression of over 63 genetranscripts following IgE-sensitization alone. Our data was validated using Real-Time-PCR; ELISA and western blot. We confirmed that IgE alone does not trigger mast cell-immediate responses, such as calcium signals, degranulation or protein-phosphorylation.

Conclusion: This report represents a substantial advance in our understanding of the genome wide effects triggered by "passive sensitization" or active stimulation of human mast cells, supporting mast cells' potential involvement in a wide range of inflammatory responses.

\section{Background}

Mast cells are best known for their role in immunoglobulin $\mathrm{E}$ (IgE)-dependent allergic responses as one of the most powerful reactions of the immune system [1]. Recent studies suggest that mast cells may also be involved in innate and adaptive immunity by producing high levels of chemokines and cytokines [1-3]. Mast cells are derived from haematopoietic progenitor cells that enter nearly all vascularized tissues, where they complete their maturation and, in some cases, can migrate into epithelia [1-4]. After appropriate activation, such as the aggregation of the high affinity IgE receptor (Fc\&RI), mast cells can produce a range of pro-inflammatory mediators, including cytokines and chemokines [5,6]. Crosslinking of FceRI- 
bound IgE with multivalent antigen initiates the activation of mast cells by promoting the aggregation of FcERI $[7,8]$. This FceRI-dependent cell activation process has three major outcomes: degranulation, secretion of preformed mediators stored in cytoplasmic granules - these granules contain vasoactive amines, neutral proteases, proteoglycans and some cytokines and growth factors; the de novo synthesis of pro-inflammatory lipid mediators (such as eicosanoids); and the synthesis and secretion of cytokines and chemokines [4-8].

Mast cells are regarded as key effector cells in IgE-associated immediate hypersensitivity reactions and allergic conditions, as well as in certain immune responses to parasites [9]. Because the IgE dependent release of proinflammatory mediators can begin within minutes of antigen challenge, the crucial role of mast cells in acute allergic reactions, such as anaphylaxis and acute attacks of atopic asthma, is now widely accepted $[4,5,7,8]$. On the other hand, the role of mast cells in chronic inflammation and other long-term tissue changes that are observed in some IgE associated diseases, including asthma, still debated [10]. However, in recent studies it is suggested that mast cells can markedly enhance antigen-dependent airway hyper reactivity, airway eosinophil infiltration, and the increased number of proliferating cells in the airway epithelium [11-14]. These reports and other lines of evidence, suggest that a key role of mast cells in IgEassociated immune responses is to amplify both acute and long-term local tissue responses to relatively weak biological signals $[5,9,11,12]$. Moreover, through their ability to release immunoregulatory cytokines, and perhaps through other mechanisms, mast cells might also influence the development, strength and persistence of Thelper 2 cell-associated immunity. However, such immunoregulatory functions of mast cells have not been fully characterized. Mast cells have also been proposed to play a role in mediating bacterial clearance by releasing cytokines, and by ingesting and killing opsonized bacteria, suggesting that mast cells have a physiological role in modulating host defenses against infectious agents [13].

Mast cell products, such as tryptase and histamine, can influence the immune-response by recruiting neutrophils or by activating other immune-effector cells [14]. These previous findings show that mast cells, apart from being principal players in allergies, appear have effects in the initiation and regulation of innate immunity. There is increasing evidence demonstrating that the innate and adaptive immune systems cooperate through shared signaling mechanisms, and very recently it was shown that mast cells may regulate the recruitment of T-cells to lymph nodes [15]. Several groups have carried out limited gene expression profiles of mast cells, without any stimuli [1618]; stimulated by cytokines [19]; triggered by antigens and in response to the inhibition of calcium-ATPase [20]; or stimulated by TLR4 [21]; or focused on the cytokine/ chemokine profile triggered by FceRI aggregation [21-23]. A recent study has shown that IgE alone can induce the release of the interlukin- 8 (IL-8) and of the monocyte chemoattractant protein 1 (MCP-1) [24]. However, many aspects of the genetic responses triggered by IgE-antigen on human mast cells are still unclear, such as the overall genetic responses to IgE sensitization alone, or widegenome expression profile triggered by FceRI aggregation. Thus, we decided to analyze the differential gene expression profile of 8,793 fully-annotated genes, after IgE sensitization, and following FceRI aggregation.

The data we present here show that, over 559 genes were differentially regulated in the stimulated cells, when compared to unstimulated cells (basal). A substantial number of genes were regulated by IgE sensitization alone; and following FceRI aggregation, a wide range of genes were triggered, including genes for cytokines, chemokines, transcription factors, anti-apoptosis, and several genes involved in innate and acquired immunity. Some of the most prominent findings are the upregulation of proinflammatory cytokines and chemokines, involved in innate and adaptive immunity. We also observed the upregulation of several receptors involved in innate immune reactions. We confirmed that IgE alone does not trigger mast cell-immediate responses, such as calcium signals, degranulation or protein-tyrosine phosphorylation, whereas FceRI aggregation did indeed trigger these immediate responses. Thus, these results represent a substantial advance in our understanding of the genomewide effects triggered by the physiological "passive sensitization" or "active stimulation" of human mast cells, and suggest that mast cell activation may not only play a pivotal role in allergic responses, but may influence the regulation of other inflammatory immune responses.

\section{Results}

\section{Generation of mast cells}

Perhaps the most important factor for mast cell development, survival and proliferation is Stem-Cell Factor (SCF or c-KIT ligand) [4], although several lines of evidence also indicate IL-3 as a crucial factor for mast cell development, survival and proliferation [4]. Human mast cells are very difficult to isolate in numbers that would allow for wide-genome expression profiling studies: for that reason we isolated CD34+ progenitor hematopoietic cells from umbilical cord blood and differentiated them to mast cells by culturing with the cytokines SCF and IL-3. After culturing $\mathrm{CD}_{3} 4^{+}$progenitor cells with cytokines for 5-6 weeks, cells were characterized as Mast Cells by flow cytometry as positive for the specific mast cell marker intracellular chymase; positive c-Kit/CD117 ${ }^{+}$and $\mathrm{Fc}_{\mathrm{CRI}}{ }^{+}$, 

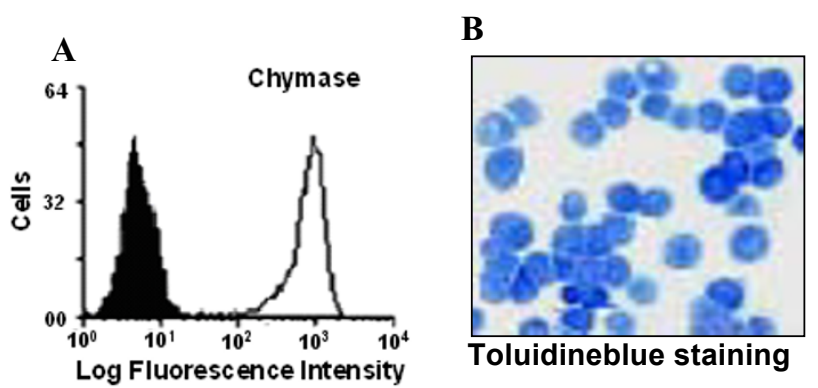

C
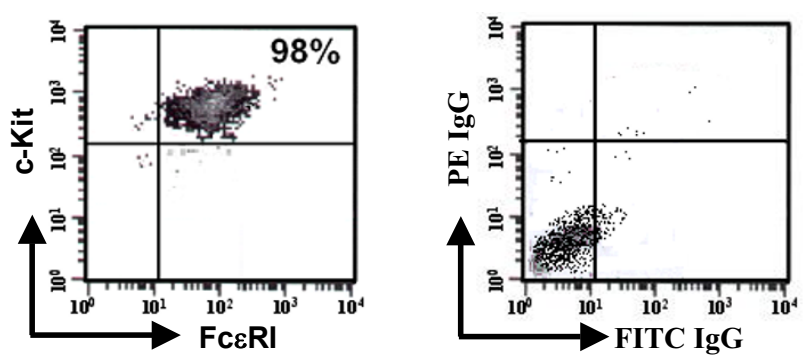

Figure I

Purity of Mast cells. A. Flow cytometry analysis of intracellular chymase expression. Human cord bloodderived mast cells labelled for intracellular mast-cell chymase expression (solid line), isotype control (Black area). Results shown are representative of four separate experiments. $\mathbf{B}$. Toluidine blue staining of mast cells. Fluorescence microscopy of human cord blood-derived mast cells stained with Toluidine blue. Results shown are representative of at least three separate experiments. C. Flow cytometry analysis of cell surface expression of c-kit and Fc\&RI. Human cord blood-derived mast cells labelled for cell-surface expression of c-kit and FceRI (left panel), and isotype controls (right panel). Results shown are representative of four separate experiments.

and by Toluidine blue staining (Figure 1). Purity was estimated at $>97 \%$.

\section{Differential gene expression profile in stimulated human mast cells}

Our aim is to study the global gene expression pattern induced by IgE sensitization and FceRI aggregation on human mast cells. Gene expression analysis using cDNA or oligo-DNA microarrays has proven to be a sensitive method to develop and refine the molecular determinants of several human disorders, including cancer and autoimmune diseases. We analyzed the expression pattern of 8,793 transcripts from the stimulated mast cells, and compared the expression patterns with control/unstimulated samples. The complete gene expression data of our experiments, representing 8,793 probeID is available at the NCBIs Gene Expression Omnibus [25], and is accessible through GEO Series accession number GSE1933 (25). The microarray analysis revealed that 760 genes $(\sim 8.6 \%)$ were differentially expressed between resting and stimulated mast cells with statistical significance $(P \leq 0.05)$, which were hierarchically clustered (Figure 2 ). Because of the relatively large number of genes that were differentially regulated, we focused on genes that were upregulated by at least a 2-fold in any time point of mast cell stimulation. Of the 760 genes, 58 genes were initially upregulated (at least 2-fold) by IgE-sensitization alone (Table. 1), and a total of 115 genes were overexpressed (by 2-fold or more in at least one time point), during the time course of mast cell activation by IgE-alone or after crosslinking FceRI (Table. 1). In order to examine the global characteristics of these genes, we used the Gene Ontology Consortium database for Biological processes [26]. Using this database we analyzed the genes that were upregulated by at least 2fold, thus, allowing us to separate the 115 genes, into the following functional families: (a) cytokines and cytokine receptors; (b) chemokines and chemokine receptors; (c) other immunoregulatory genes; $(\mathrm{d})$ cell proliferation and anti-apoptosis; (e) adhesion and cytoskeleton remodeling; (f) transcription factors and regulators of transcription; (g) signal transduction; (h) genes involved in other cellular functions "others" (Table 1 \& Figure 3)

\section{Upregulation of genes by IgE sensitization}

Our study revealed that substantial changes in gene expression in response to monomeric-IgE sensitization alone. In order to ensure that the human IgE (IgE, Cat: 30AI05, Lot number A01071004, Fitzgerald, Concord, MA), used in this study was indeed monomeric IgE, prior to each experiment; we run a sample of the IgE through nondenaturing polyachrylamide-gel-electrophosys (nonreducing-PAGE). No aggregates were observed at any time (data not shown).

We focused the analysis of our data on genes that were upregulated by at least 2-fold, over basal levels, and identified 58 genes that were increased by IgE sensitization alone (Table. 1). We then separated them into different categories, based on their biological function (determined by public databases). Among the most prominent findings was the upregulation of genes coding for the cytokines IL-1 $\beta$ (3.3 fold), IL-6 (2.7 fold), and CSF1 (1.6 fold); genes coding for the chemokines IL-8 (CXCL8) (2.1 fold), MIP1 $\beta$ (CCL4) (3.5 fold), MCP3 (CCL7) (2.1 fold), GRO $\alpha$ (CXCL1) (2.3 fold) and GRO $\gamma$ (CXCL3) (1.6 fold), were also upregulated. Other than these, several genes coding for other receptors involved in immune-responses; immunoregulatory genes; adhesion and/or cytoskeleton remodeling; regulators of apoptosis; signal transduction; transcription factors; were also upregulated by monomeric IgE (Table. 1). Thus, these results suggest that "passive" sensitization of mast cells, with monomeric IgE, may not only prime mast cells to be ready for the challenge to come, but that mast cells may also have the potential to 


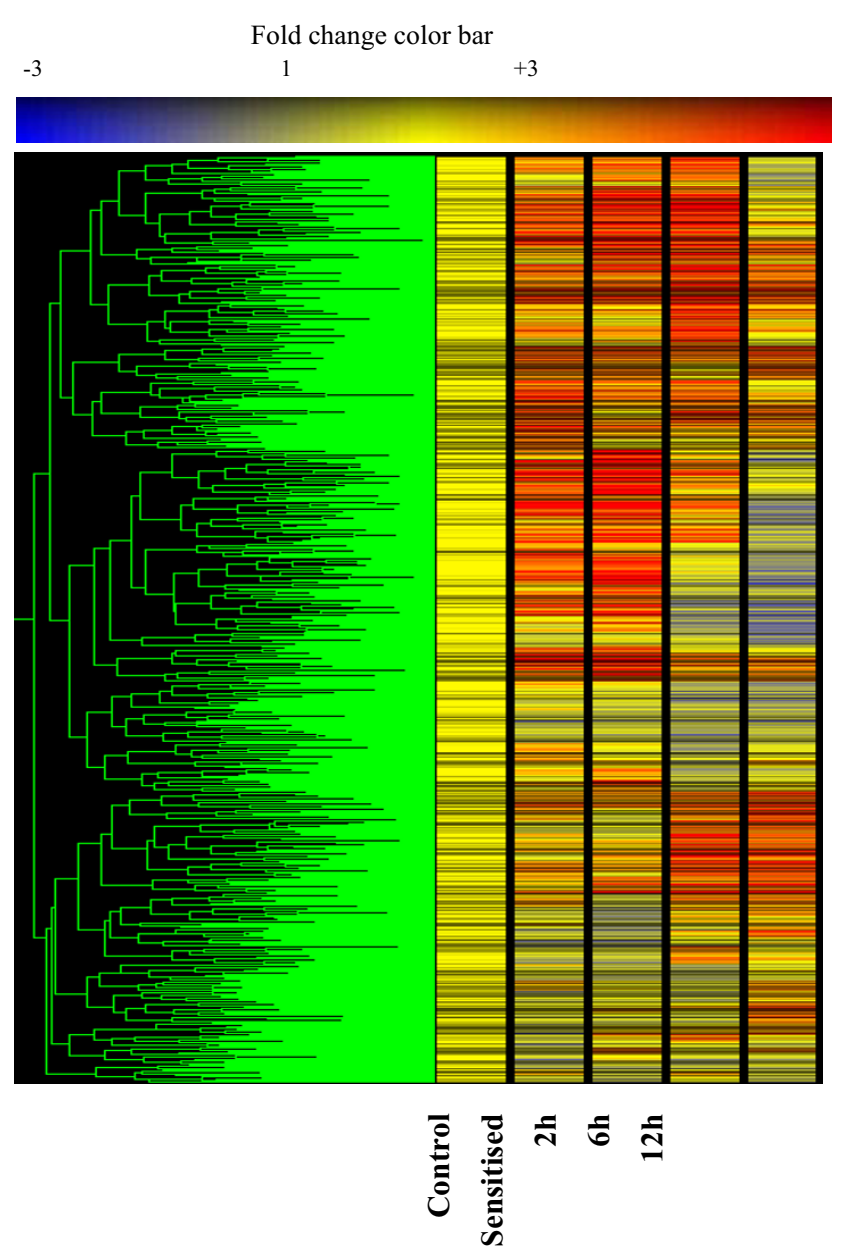

Figure 2

Changes in gene expression in human mast cells following IgE sensitization and $F \mathbf{c} \varepsilon R \mathbf{I}$ aggregation. Changes in expression over control of human cord blood derived mast cells that were activated by $\lg E$ sensitization and FceRI crosslinking for different time points $(2 \mathrm{hr}, 6 \mathrm{hr}$ and $\mathrm{I} 2$ $\mathrm{hr}$ ). Labelled cRNA from cell of each time point were hybridized to Human Genome Focus array and signals were scanned after fluidics. The data was analyzed as described in material and methods and analysis revealed differential expression of 760 genes between resting and stimulated mast cells with statistical significance $(P \leq 0.05)$. Agglomerative average-linkage hierarchical clustering of the five different experimental conditions was obtained for selected groups of genes using GeneSpring 7.0. Each colored box represents the normalized expression level of a given gene in a particular experimental condition and is colored according to the color bar. The data represent average of four independent experiments.

trigger the priming and/or recruitment of other immuneeffector cells.

\section{Gene profile of upregulated genes during various time points of mast cell stimulation cytokines/cytokine receptors and chemokines/chemokine receptors}

An interesting finding in our study was upregulation of genes coding for the pyrogenic and proinflammatory cytokines IL-1 $\beta$, IL-6 (Table. 1a). One of the key roles for IL- $1 \beta$ is to trigger the upregulation of key proinflammatory proteins [27]. We also observed the upregulation of PTX3 (pentaxin-related gene) (Table. 1c): PTX3 is a protein involved in inflammation that is rapidly upregulated by IL-1 $\beta$. Other cytokine genes that were upregulated are CSF1 (a growth promoting cytokine), and the cytokine receptors IL1R1, IL27RA, TNFRSF9, TNFRSF12 and IL1RN (Table. 1a). We also found that the level of expression of genes coding for the chemokines IL-8 (CXCL8), CCL7 (MCP3), CCL4 (MIP1 $\beta$ ) and CXCL1 (GRO $\alpha$ ) was increased (Table 1b). IL-8 plays a major role in inflammatory responses mainly due to its ability to recruit and activate neutrophils. CCL7, CCL4 and CXCL1 are known to recruit monocytes, NK, basophils, dendritic cells and TH2 cells. Moreover, our data also show that several other chemokine genes were upregulated during mast cell stimulation: these include CCL5 (RANTES), CXCL3 (GRO $\gamma$ ), and the chemokine receptor CCRL2 (Table. 1b). These data suggest a key role for FceRI in triggering an a wide range of inflammatory responses, as the over-expression of cytokines and chemokines is a prerequisite to triggering inflammation, including vascular permeability, and leukocyte and lymphocyte recruitment, differentiation and activation.

\section{Other immune-regulatory genes}

Several genes involved in innate and adaptive immuneresponse were upregulated at least by 2 -fold during mast cell stimulation: these include the Toll Like Receptor 2 (TLR2), as well as several genes of the TNF $\alpha$ signaling pathways, including TNFAIP6 (Table. 1c). These findings support previous reports of the role of mast cells in innate immunity and antibacterial activity [21]. Transcripts of genes LIF, CD69, and CD83 were also upregulated, as were the major histocompatibility complex genes (HLA-DQB1, and HKE2) and inhibitory receptor of IgG, FCGR2B (Table. 1c). The generation of transcripts for such genes suggests that mast cells can acquire characteristics typical of cells involved in innate and adaptive immune responses.

\section{Cell proliferation and anti-apoptosis}

Several genes involved in cell proliferation and survival, such as PDGFA (platelet-derived growth factor alpha polypeptide), PDGFB (platelet-derived growth factor beta polypeptide), PBEF1 (pre-B-cell colony-enhancing factor), TIEG (TGFB inducible early growth response), and INSIG1 (insulin induced gene 1) were upregulated, as well as several anti-apoptosis genes including TNFAIP3 
Table I: Differentiated, human cord blood-derived, mast cells were sensitized overnight by the addition of monomeric IgE followed by crosslinking the high affinity IgE receptors, Fc\&RI using anti IgE for $2 \mathrm{~h}, 6 \mathrm{~h}$ and $\mathrm{I} 2 \mathrm{~h}$. Gene expression profile at each time point were analyzed and I 15 genes, which were upregulated 2 fold or more (over control/unstimulated cells) atleast in one point have been selected and classified according to their biological functions as a) Cytokines and cytokine receptors b) Chemokine and chemokine receptors $c$ ) Other immunoregulatory genes d)Cell proliferation and anti-apoptosis e)Adhesion and cytoskeleton remodeling f)Transcription factors and regulators g) Signal transduction h) Other genes. Fold change is expressed as fold-increase over control/ unsensitized samples, and representative of four separate experiments.

a. Cytokines and cytokine receptors

\begin{tabular}{|c|c|c|c|c|c|c|}
\hline Genbank ID & Gene symbol & Gene name & IgE Sens & $2 \mathrm{~h}$ & $6 \mathrm{~h}$ & $12 \mathrm{~h}$ \\
\hline MI5330 & ILIB & Interleukin I, beta & 3.3 & 4.8 & 1.5 & -2.0 \\
\hline NM 000600.1 & IL6 & Interleukin 6 & 2.0 & 2.6 & 1.9 & -1.3 \\
\hline M37435 & CSFI & Colony stimulating factor I & 1.6 & 4.5 & 1.9 & -1.4 \\
\hline NM 000877.1 & ILIRI & Interleukin I receptor, type I & 1.4 & 2.2 & 1.9 & -1.2 \\
\hline Al983II5 & IL27RA & Class I cytokine receptor & 1.4 & 1.3 & 2.6 & I.I \\
\hline NM 001561.2 & TNFRSF9 & Tumor necrosis factor receptor superfamily, member 9 & 1.2 & 1.5 & 2.5 & 1.7 \\
\hline NM 016639.1 & TNFRSFI $2 A$ & Tumor necrosis factor receptor superfamily, member I2A & 1.5 & 2.4 & -1.3 & -1.9 \\
\hline$\times 52015$ & ILIRN & Interleukin I receptor antagonist & I.I & 2.4 & 2.6 & 1.4 \\
\hline
\end{tabular}

b. Chemokine and chemokine receptors

\begin{tabular}{|c|c|c|c|c|c|c|}
\hline Genbank ID & Gene symbol & Gene name & IgE Sens & $2 \mathrm{~h}$ & $6 \mathrm{~h}$ & $12 \mathrm{~h}$ \\
\hline NM 002984.I & $C C L 4$ & Chemokine (C-C motif) ligand 4 & 3.5 & 4.7 & 1.6 & -3.0 \\
\hline NM 001511.1 & CXCLI & Chemokine (C-X-C motif) ligand I & 2.3 & 2.5 & 1.1 & -2.9 \\
\hline NM 006273.2 & CCL7 & Chemokine (C-C motif) ligand 7 & 2.1 & 3.6 & 5.3 & 2.2 \\
\hline NM 002090.1 & $C X C L 3$ & Chemokine ( $\mathrm{C}-\mathrm{X}-\mathrm{C}$ motif) ligand 3 & 1.6 & 2.5 & 1.6 & -1.8 \\
\hline NM 002985.I & CCL5 & Chemokine (C-C motif) ligand 5 & 1.6 & 1.8 & 2.1 & 1.8 \\
\hline AFOI5524 & CCRL2 & Chemokine (C-C motif) receptor-like 2 & 1.5 & 2.0 & 2.0 & 1.2 \\
\hline AF043337 & IL8 & Interleukin 8 & 2.1 & 2.1 & 1.5 & -1.5 \\
\hline
\end{tabular}

c. Other immunoregulatory genes

\begin{tabular}{|c|c|c|c|c|c|c|}
\hline Genbank ID & Gene symbol & Gene name & IgE Sens & $2 \mathrm{~h}$ & $6 \mathrm{~h}$ & $12 \mathrm{~h}$ \\
\hline S59049 & BL34 & B cell activation gene & 3.4 & 6.8 & -2.3 & -3.9 \\
\hline NM 002309.2 & LIF & Leukemia inhibitory factor (Cholinergic differentiation factor) & -1.3 & 5.1 & -1.3 & -4.0 \\
\hline$\underline{L 07555}$ & CD69 & CD69 antigen & -1.1 & 4.1 & -1.0 & -1.7 \\
\hline AF036906 & LAT & Linker for activation of $T$ cells & 1.9 & 2.3 & 2.3 & 1.7 \\
\hline NM 004233.1 & CD83 & CD83 antigen & 2.4 & 3.0 & 1.6 & -1.2 \\
\hline NM 000675.2 & ADORA2A & Adenosine $\mathrm{A} 2 \mathrm{a}$ receptor & 2.1 & 3.8 & 1.4 & -1.3 \\
\hline NM 001311.1 & CRIPI & Cysteine-rich protein I & 1.5 & 2.6 & 2.7 & 1.3 \\
\hline M16276 & $H L A-D Q B I$ & Major histocompatibility complex, class II, DQ beta I & 1.9 & 2.0 & 1.7 & 1.2 \\
\hline$\overline{A W 007185}$ & HKE2 & HLA class II region expressed gene KE2 & 1.4 & 1.4 & 2.2 & 1.9 \\
\hline NM 005658.1 & TRAFI & TNF receptor-associated factor I & 1.5 & 2.5 & 1.8 & -1.0 \\
\hline NM 005601 & NKG7 & Natural killer cell group 7 sequence & 1.4 & 2.2 & 1.3 & 1.3 \\
\hline NM 002852.1 & PTX3 & Pentaxin-related gene, rapidly induced by IL-I beta & 1.8 & 2.5 & 1.5 & -2.1 \\
\hline M31933 & FCGR2B & Fc fragment of IgG, low affinity llb, receptor for (CD32) & 2.0 & 2.0 & 1.3 & -1.1 \\
\hline NM 007II5.I & TNFAIP6 & Tumor necrosis factor, alpha-induced protein 6 & 2.0 & 2.4 & 2.1 & -1.1 \\
\hline NM 000956.1 & PTGER2 & Prostaglandin E receptor 2 (subtype EP2) & 2.0 & 2.2 & 1.3 & -1.5 \\
\hline$\overline{N M 013252.1}$ & CLECSF5 & C-type lectin, superfamily member 5 & 1.6 & 2.3 & 2.5 & 1.2 \\
\hline NM 00495I.I & $E B / 2$ & Epstein-Barr virus induced gene 2 (lymphocyte-specific GPCR) & 1.4 & 2.0 & -1.7 & -2.0 \\
\hline NM 018643.1 & TREMI & Triggering receptor expressed on myeloid cells I & 1.4 & 2.2 & 2.5 & 1.7 \\
\hline U37546 & BIRC3 & Baculoviral IAP repeat-containing 3 & 1.4 & 2.0 & 1.1 & -1.1 \\
\hline NM 002000.1 & FCAR & Fc fragment of $\lg A$, receptor for & 1.4 & 2.0 & 1.7 & -1.9 \\
\hline NM 003264.I & $T L R 2$ & Toll-like receptor 2 & 1.4 & 2.0 & 2.0 & -1.6 \\
\hline NM 002114.1 & HIVEPI & Human immunodeficiency virus type I enhancer binding protein I & 2.0 & 1.6 & -1.2 & -1.6 \\
\hline
\end{tabular}

\section{d. Cell proliferation and anti-apoptosis}


Table I: Differentiated, human cord blood-derived, mast cells were sensitized overnight by the addition of monomeric IgE followed by crosslinking the high affinity IgE receptors, Fc\&RI using anti IgE for $2 \mathrm{~h}, 6 \mathrm{~h}$ and $\mathrm{I} 2 \mathrm{~h}$. Gene expression profile at each time point were analyzed and II 5 genes, which were upregulated 2 fold or more (over control/unstimulated cells) atleast in one point have been selected and classified according to their biological functions as a) Cytokines and cytokine receptors b) Chemokine and chemokine receptors c) Other immunoregulatory genes d)Cell proliferation and anti-apoptosis e)Adhesion and cytoskeleton remodeling f)Transcription factors and regulators g) Signal transduction $h$ ) Other genes. Fold change is expressed as fold-increase over control/ unsensitized samples, and representative of four separate experiments. (Continued)

\begin{tabular}{|c|c|c|c|c|c|c|}
\hline Genbank ID & Gene symbol & Gene name & IgE Sens & $2 \mathrm{~h}$ & $6 \mathrm{~h}$ & $12 \mathrm{~h}$ \\
\hline NM 006732.1 & FOSB & FBJ murine osteosarcoma viral oncogene homolog $B$ & 2.1 & 3.9 & -3.0 & -4.9 \\
\hline NM 004430.1 & EGR3 & Early growth response 3 & 1.8 & 7.5 & -1.4 & -3.3 \\
\hline AF00I294 & PHLDA2 & Tumor suppressing subtransferable candidate 3 & 2.6 & 3.8 & 1.7 & -1.2 \\
\hline NM 002575.1 & SERPINB2 & Serine (or cysteine) proteinase inhibitor, clade B (ovalbumin), member 2 & 1.9 & 3.8 & 5.2 & -1.1 \\
\hline M60485 & FGFRI & $\begin{array}{l}\text { Ffibroblast growth factor receptor I (fms-related tyrosine kinase 2, Pfeiffer } \\
\text { syndrome) }\end{array}$ & 2.3 & 2.2 & 2.7 & 1.5 \\
\hline NM 000399.2 & EGR2 & Early growth response 2 (Krox-20 homolog, Drosophila) & 1.6 & 2.7 & 1.6 & -1.9 \\
\hline NM 005542.3 & INSIGI & Insulin induced gene I & 1.7 & 2.8 & 1.6 & -1.2 \\
\hline NM 002607.I & PDGFA & Platelet-derived growth factor alpha polypeptide & 1.8 & 2.4 & 1.7 & 1.1 \\
\hline NM 003897.1 & IER3 & Immediate early response 3 & 1.8 & 3.0 & -1.2 & -2.3 \\
\hline NM 002608.1 & PDGFB & Platelet-derived growth factor beta polypeptide & 1.2 & 2.0 & -1.2 & 1.0 \\
\hline NM 006763.1 & BTG2 & BTG family, member 2 & 1.5 & 2.0 & -1.1 & -1.9 \\
\hline NM 005655.1 & TIEG & TGFB inducible early growth response & 1.8 & 1.9 & -1.8 & -2.4 \\
\hline NM_004073.I & CNK & Cytokine-inducible kinase & 1.2 & 1.8 & -1.5 & -2.4 \\
\hline BF5755I4 & PBEFI & Pre-B-cell colony-enhancing factor & 1.6 & 1.9 & -1.3 & -3.2 \\
\hline NM 006290.1 & TNFAIP3 & TNF-induced protein 3 & 2.7 & 3.4 & 1.8 & -1.0 \\
\hline $\mathrm{BC} 005352$ & TNFAIP8 & TNF-induced protein 8 & 2.0 & 1.6 & 1.3 & 1.3 \\
\hline NM 023009.1 & $M L P$ & MARCKS-like protein & 1.5 & 1.7 & 2.5 & I.I \\
\hline NM 001878.2 & CRABP2 & Cellular retinoic acid binding protein 2 & 1.1 & 1.2 & 1.4 & 2.0 \\
\hline NM 002199.2 & IRF2 & Interferon regulatory factor 2 & -1.5 & -1.7 & 1.2 & 2.0 \\
\hline
\end{tabular}

e. Adhesion and cytoskeleton remodeling

\begin{tabular}{|c|c|c|c|c|c|c|}
\hline Genbank ID & Gene symbol & Gene name & IgE Sens & $2 \mathrm{~h}$ & $6 \mathrm{~h}$ & $12 \mathrm{~h}$ \\
\hline NM 004658.1 & RASALI & RAS protein activator like I (GAPI like) & 2.2 & 2.2 & 3.6 & 2.3 \\
\hline NM 013231.1 & FLRT2 & Fibronectin leucine rich transmembrane protein 2 & 1.4 & 2.3 & 2.3 & 2.4 \\
\hline NM 003078.1 & SMARCD3 & $\begin{array}{l}\text { SWI/SNF related, matrix associated, actin dependent regulator of chromatin, } \\
\text { subfamily d, member } 3\end{array}$ & 2.2 & 1.9 & 1.2 & 1.1 \\
\hline BG054844 & ARHE & Ras homolog gene family, member $\mathrm{E}$ & 1.3 & 2.2 & 1.9 & -1.0 \\
\hline NM 000216.1 & KALI & Kallmann syndrome I sequence & 1.4 & 1.4 & 1.3 & 2.0 \\
\hline M62994 & FLNB & Filamin B, beta (actin binding protein 278 ) & 1.2 & 1.4 & 2.0 & 1.0 \\
\hline NM 004357.1 & $C D / 5 I$ & CDI5I antigen & 1.0 & 1.2 & 2.1 & -1.1 \\
\hline AA243143 & ARF6 & ADP-ribosylation factor 6 & 2.1 & 1.3 & 1.1 & 1.0 \\
\hline NM 001627.2 & ALCAM & Activated leukocyte cell adhesion molecule & 1.1 & I.I & 1.7 & 2.0 \\
\hline
\end{tabular}

f. Transcription factors and regulators

\begin{tabular}{|c|c|c|c|c|c|c|}
\hline Genbank ID & Gene symbol & Gene name & IgE Sens & $2 \mathrm{~h}$ & $6 \mathrm{~h}$ & $12 \mathrm{~h}$ \\
\hline ALO21977 & MAFF & V-maf musculoaponeurotic fibrosarcoma oncogene homolog $\mathrm{F}$ (avian) & 2.6 & 6.3 & 1.2 & -2.2 \\
\hline AF060154 & MSC & Musculin (activated B-cell factor-I) & 1.8 & 2.4 & 1.9 & 1.1 \\
\hline M55643 & NFKBI & Nuclear factor of kappa light polypeptide gene enhancer in B-cells I (pI05) & 1.7 & 2.1 & 1.5 & -1.0 \\
\hline NM 001706.I & $B C L 6$ & B-cell CLL/lymphoma 6 & 2.4 & 2.0 & 1.5 & 1.2 \\
\hline 008015 & NFATCI & Nuclear factor of activated T-cells, cytoplasmic, calcineurin-dependent I & 1.3 & 2.3 & -1.1 & -1.1 \\
\hline NM 001674.2 & ATF3 & Activating transcription factor 3 & 1.3 & 2.0 & -1.0 & -1.6 \\
\hline A1078167 & NFKBIA & $\begin{array}{l}\text { Nuclear factor of kappa light polypeptide gene enhancer in B-cells inhibitor, } \\
\text { alpha }\end{array}$ & 1.9 & 2.0 & 1.3 & -1.5 \\
\hline NM 004556.1 & NFKBIE & $\begin{array}{l}\text { Nuclear factor of kappa light polypeptide gene enhancer in B-cells inhibitor, } \\
\text { epsilon }\end{array}$ & 1.7 & 2.0 & 1.1 & -1.2 \\
\hline NM 002467.1 & MYC & V-myc myelocytomatosis viral oncogene homolog (avian) & 1.7 & 2.1 & 1.1 & -1.3 \\
\hline NM 001423.1 & EMPI & Epithelial membrane protein I & 1.4 & 1.6 & 2.1 & 1.3 \\
\hline NM 012081 & ELL2 & ELL-related RNA polymerase II, elongation factor & 1.7 & 1.3 & 2.6 & 1.3 \\
\hline NM 001067.2 & TOP2A & Topoisomerase (DNA) II alpha I70kDa & 2.0 & 1.0 & 1.2 & 1.3 \\
\hline
\end{tabular}


Table I: Differentiated, human cord blood-derived, mast cells were sensitized overnight by the addition of monomeric IgE followed by crosslinking the high affinity IgE receptors, Fc\&RI using anti IgE for 2 h, 6 h and I 2 h. Gene expression profile at each time point were analyzed and II 5 genes, which were upregulated 2 fold or more (over control/unstimulated cells) atleast in one point have been selected and classified according to their biological functions as a) Cytokines and cytokine receptors b) Chemokine and chemokine receptors c) Other immunoregulatory genes d)Cell proliferation and anti-apoptosis e)Adhesion and cytoskeleton remodeling f) Transcription factors and regulators g) Signal transduction h) Other genes. Fold change is expressed as fold-increase over control/ unsensitized samples, and representative of four separate experiments. (Continued)

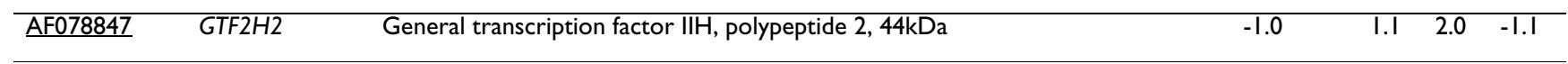

g. Signal transduction

\begin{tabular}{|c|c|c|c|c|c|c|}
\hline Genbank ID & Gene symbol & Gene name & IgE Sens & $2 \mathrm{~h}$ & $6 \mathrm{~h}$ & $12 \mathrm{~h}$ \\
\hline NM 004418.2 & DUSP2 & Dual specificity phosphatase 2 & 4.3 & 7.2 & 1.8 & 1.5 \\
\hline NM 000361.1 & $T H B D$ & Thrombomodulin & 2.5 & 4.5 & 1.0 & -1.7 \\
\hline S77154 & $N R 4 A 2$ & Nuclear receptor subfamily 4, group A, member 2 & 1.3 & 4.1 & -1.0 & -2.1 \\
\hline$\overline{N M 005261.1}$ & GEM & GTP binding protein overexpressed in skeletal muscle & 1.2 & 2.7 & 1.1 & -1.1 \\
\hline AF035776 & OLRI & Oxidised low density lipoprotein (lectin-like) receptor I & 2.0 & 2.6 & 3.1 & -1.0 \\
\hline NM 000161.1 & $\mathrm{GCHI}$ & GTP cyclohydrolase I (dopa-responsive dystonia) & 2.0 & 2.4 & 1.7 & -1.9 \\
\hline NM 021972.1 & SPHKI & Sphingosine kinase I & 1.4 & 2.1 & 2.7 & -1.0 \\
\hline NM 005001.1 & NDUFA7 & NADH dehydrogenase (ubiquinone) I alpha subcomplex, $7,14.5 \mathrm{kDa}$ & 1.6 & 1.6 & 2.0 & 1.4 \\
\hline M60278 & HBEGF & Heparin-binding EGF-like growth factor & 1.1 & 2.4 & -2.1 & -5.0 \\
\hline $\mathrm{U77914}$ & $J A G I$ & Jagged I (Alagille syndrome) & 1.4 & 2.5 & 1.8 & 1.0 \\
\hline NM 000527.2 & LDLR & Low density lipoprotein receptor & 1.6 & 2.0 & -1.8 & -1.4 \\
\hline NM 005904.1 & MADH7 & MAD, mothers against decapentaplegic homolog 7 (Drosophila) & 1.7 & 1.9 & -1.2 & -2.0 \\
\hline AF070528 & MALTI & Mucosa associated lymphoid tissue lymphoma translocation gene I & 1.5 & 2.1 & 1.2 & -1.2 \\
\hline NM 005842.1 & SPRY2 & Sprouty homolog 2 (Drosophila) & 1.1 & 2.2 & 1.4 & -1.3 \\
\hline$\overline{\mathrm{BC} 003143}$ & DUSP6 & Dual specificity phosphatase 6 & 1.2 & 2.2 & 1.2 & -1.4 \\
\hline$\overline{\mathrm{AA78038I}}$ & MAP2K3 & Mitogen-activated protein kinase kinase 3 & -1.0 & 2.1 & -1.0 & -1.7 \\
\hline NM 001881.1 & CREM & cAMP responsive element modulator & 1.2 & 2.0 & -1.0 & -1.1 \\
\hline$\overline{N M 004417.2}$ & DUSPI & Dual specificity phosphatase I & 1.6 & 1.8 & -2.3 & -3.3 \\
\hline NM 003954.1 & MAP3KI4 & Mitogen-activated protein kinase kinase kinase 14 & 1.5 & 2.0 & 1.3 & 1.4 \\
\hline AF305083 & FUT4 & Fucosyltransferase 4 (alpha $(1,3)$ fucosyltransferase, myeloid-specific) & 2.0 & 1.6 & 1.2 & -1.5 \\
\hline BE327172 & JUN & V-jun sarcoma virus 17 oncogene homolog & 1.7 & 1.5 & 1.4 & 2.0 \\
\hline$\underline{\underline{L 06633}}$ & PSCDBP & Pleckstrin homology, Sec7 and coiled/coil domains, binding protein & 1.3 & 1.6 & 2.0 & 1.1 \\
\hline MI4333 & FYN & FYN oncogene related to SRC, FGR, YES & 1.3 & 1.5 & 3.7 & 1.6 \\
\hline NM_005023.1 & PGGTIB & Protein geranylgeranyltransferase type I, beta subunit & 1.7 & 1.4 & 1.5 & 2.1 \\
\hline NM 006296.1 & VRK2 & Vaccinia related kinase 2 & 1.3 & 1.4 & 2.0 & -1.1 \\
\hline $\mathrm{AFI} 2748 \mathrm{I}$ & proto- $L B C$ & A kinase (PRKA) anchor protein 13 & 1.4 & -1.1 & 1.3 & 2.0 \\
\hline NM 003318.1 & TTK & TTK protein kinase & 1.6 & -1.1 & 2.1 & 1.6 \\
\hline
\end{tabular}

\section{h. Other genes}

\begin{tabular}{|c|c|c|c|c|c|c|}
\hline Genbank ID & Gene symbol & Gene name & IgE Sens & $2 \mathrm{~h}$ & $6 \mathrm{~h}$ & $12 \mathrm{~h}$ \\
\hline NM 003633.1 & ENCI & Ectodermal-neural cortex (with BTB-like domain) & 2.2 & 3.1 & I.I & 1.4 \\
\hline NM 004694.I & SLCI6A6 & Solute carrier family 16 (monocarboxylic acid transporters), member 6 & 2.6 & 2.5 & 1.0 & 1.4 \\
\hline AA451996 & HIST2H2AA & $\mathrm{H} 2 \mathrm{~A}$ histone family, member $\mathrm{O}$ & 2.3 & 2.4 & 2.4 & 1.4 \\
\hline AFI82273 & CYP3A4 & Cytochrome P450, subfamily IIIA (niphedipine oxidase), polypeptide 4 & 1.2 & 2.0 & 1.0 & I.I \\
\hline$\overline{\mathrm{BC} 002649}$ & HISTIHIC & Histone I, Hic & 2.1 & 1.8 & 2.0 & 1.7 \\
\hline NM 006101.1 & HEC & Highly expressed in cancer, rich in leucine heptad repeats & 2.3 & 1.3 & 2.1 & 1.6 \\
\hline NM 004760.1 & STKI TA & Serine/threonine kinase $17 \mathrm{a}$ & 1.4 & 1.8 & 2.0 & -1.1 \\
\hline NM 020651.2 & PELII & Pellino homolog I (Drosophila) & 2.2 & 1.4 & 1.4 & 1.0 \\
\hline L39833 & KCNABI & Potassium voltage-gated channel, shaker-related subfamily, beta member I & 2.4 & 1.4 & I.I & 1.4 \\
\hline BF223021 & B4GALT4 & UDP-Gal:betaGIcNAc beta I,4-galactosyltransferase, polypeptide 4 & 2.0 & 1.2 & 1.5 & 1.2 \\
\hline
\end{tabular}


A Distribution of all upregulated genesinto
functionalfamilies as $\%$ of the total $100 \%$ (1\%\%
B

\section{Distributionof genes upregulated byIgEalone into functional families as $\%$ of the total $100 \%$}

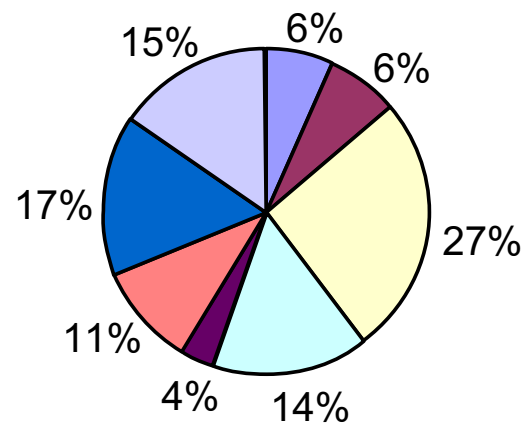

$\square$ Cytokines and cytokine receptors

$\square$ Chemokines and chemokines receptors

$\square$ Other immune regulatory genes

$\square$ Cell proliferation and anti-apoptosis

Adhesion and cytoskeleton remodeling

$\square$ Transcription factors/regulators of transcription

Signal transduction

$\square$ Other genes

\section{Figure 3}

Pie chart showing the percentage distribution of the upregulated genes. A. Percentage distribution of the total amount of genes upregulated. All the genes, observed to be upregulated at least 2-fold at any given time point, were distributed, according to their biological function described in table I. B. Percentage distribution of genes upregulated by IgE alone. Distribution, according to biological function, of the genes observed to be upregulated during IgE sensitization (IgE alone).

(TNF-alpha-induced protein 3), TNFAIP8 (TNF-alphainduced protein 8 ), IER3 (immediate early response 3), SERPINB2 (serine or cysteine proteinase inhibitor B2), and IRF2 (interferon regulatory factor 2) (Table. 1d). This supports the fact that, in the initial stages of mast cell activation, several mediators produced are mainly for cell proliferation and survival [28]. Thus, FceRI aggregation may enhance mast cell proliferation and survival, perhaps owing to the autocrine effects of the cytokines, growth factors, and antiapoptotic proteins, triggered by FceRI aggregation.

\section{Cell adhesion and cytoskeleton remodeling}

Another functional characteristic of immune-cell activation is the coordinated expression of genes involved in cell adhesion and cytoskeleton remodeling (Table. 1e). Of particular importance are the genes coding for proteins involved in cell motility, cytokinesis, endocytosis and exocytosis. We found at least 2-fold upregulation of various genes coding for proteins involved in cell adhesion, such as FLRT2 (fibronectin leucine rich transmembrane protein 2), KAL1 (Kallmann syndrome 1 sequence), CD151 (CD151 antigen), and ALCAM (activated leukocyte cell adhesion molecule); as well as for several gene-transcripts involved in cytoskeleton remodeling, including RASAL1
(RAS protein activator like 1), ARHE (RAS homolog gene family, member E), ARF6 (ADP-ribosylation factor 6), and FLNB (filamin B, $\beta$-actin binding protein 278) (Table. $1 e$ ). The expression of genes involved in cell adhesion and cytoskeleton remodeling is an essential step in immunecell activation. Resting immune cells have cytoskeletal structures that sequester antigen, chemokine, and adhesion receptors in accessible regions of the plasma membrane. Upon activation, reorganization of the actin cytoskeleton leads to the formation of supramolecular activation clusters, bringing receptors and costimulatory molecules together, as well as important adaptor proteins that promote the sustained activation of the cell.

\section{Transcription factors and regulators of transcription}

Stimulation of immune-effector cells through their antigen receptors initiates cell cycle entry and changes the gene expression pattern, a response generally referred to as "activation". We found that the genes for several transcription factors were upregulated during IgE-sensitization and FceRI aggregation, including the transcription factors most active during an immune response, such as $N F \kappa B$ and NFAT (Table. 1f). We observed an increase in the transcripts for the nuclear factor of kappa light polypeptide genes 1, alpha, and epsilon (NFkB 1, 1A, and 1E), and 
the nuclear factor of activated T cells, NFATC1 (Table. 1f). Other transcription factors upregulated were the oncogenes MYC (v-myc myelo-cytomatosis viral oncogene homolog), and MAFF (v-maf musculo-aponeurotic fibrosarcoma oncogene homolog F) (Table. 1f). Interestingly, the activities of NFKB and NFAT together are responsible for the transcription of many proinflammatory genes, including several genes coding for cytokines and chemokines $[29,30]$.

\section{Signal transduction}

During mast cell activation, many signaling molecules are engaged in diverse responses, ranging from calcium release from internal stores, degranulation, the generation of lipid-derived proinflammatory mediators and the production of cytokines and chemokines. In our study we observed that a substantial number of genes coding for intracellular signaling proteins were upregulated, by at least 2-fold (Table. 1g). These include genes for serine protein kinases of the Mitogen Activated Protein Kinase family, such as MAP2K3 and MAP3K14: members of this family of kinases not only play a role in mitogenesis, but can potentially lead to the activation of transcription factors. The gene coding for the tyrosine kinase FYN (FYN oncogene related to SRC, FGR, YES) was also upregulated (Table. 1g): FYN is a member of the Src-tyrosine kinase family; members of this family are critical for the signal transduction cascades triggered by all antigen receptors including by FceRI, TCR, Fc $\gamma$ Rs, and the B-cell antigen receptor. Several genes coding for protein phosphatases were also upregulated, including several members of the dual specificity phosphatase family coding for DUSP1, DUSP2, and DUSP6 (Table. 1g). Moreover, we show here the upregulation of genes that code for oxidized low density lipoprotein receptor (OLR1), and for the low density lipoprotein receptor $(L D L R)$ (Table. $1 \mathrm{~g}$ ), indicating a potential role for mast cells in cholesterol homeostasis. Of particular interest is the upregulation of the gene coding for the lipid kinase, sphingosine kinase 1 (SPHK1) (Table. $1 \mathrm{~g}$ ). We and others have previously reported that SPHK1 plays a critical role in the intracellular signaling pathways triggered by FceRI in mast cells [28,31], and coordinates several physiological responses triggered by activated mast cells.

\section{Real time PCR}

We confirmed our microarrays findings by Real time PCR on selected genes such as $I L-1 \beta I L 6, I L-8, M C P 3$, RANTES and SPHK1, utilizing an aliquot of the same RNA sample that was used for the microarray experiments (Figure 4). The results showed that the messenger RNA for the selected genes follows a similar pattern of expression to that observed with the oligo-DNA microarray experiment, thus confirming the results and the quality of the data obtained with the high-density microarrays.

\section{Protein expression by ELISA}

Mast cell activation also results in the sustained de novo production of pro-inflammatory cytokines and chemokines both of which may contribute to the inflammation and pathology underlying allergic disease as well as in innate and acquired immunity. The amounts of these cytokines were measured by ELISA and depicted in Figure $5 A$. FceRI-triggered generation of IL-1 $\beta$, IL-6, IL-8, CCL7 (MCP3) and CCL5 (RANTES), whereas IgE sensitization alone triggered smaller amounts of IL- $1 \beta$ and MCP3, high amount of IL-8, and very less amounts of IL- 6 and RANTES (Figure 5A).

\section{Protein expression by Western blot}

We verified the differential expression of SPHK1 by Western blot analysis (Figure 5B). Its levels of expression were found to be consistent with that of microarray as well as Real Time PCR results. Thus, these data together with Real Time PCR data validate microarray results.

\section{Mast cells show strong activation by FcERI aggregation but not by IgE-sensitization}

Mast cell activation via FceRI triggers exocytosis of granules containing pre-formed inflammatory mediators in a tyrosine kinase and calcium dependent manner. Here we studied, whether monomeric-IgE alone, may activate FceRI intracellular signaling pathways, leading to physiological responses of mast cells, by analyzing the overall tyrosine phosphorylation; fluctuations in cytosolic $\mathrm{Ca}^{2+}$ concentration; and degranulation by measuring $\beta$-hexosaminidase release (Fig. 6A,B \&6C). We show here that in our experimental setting monomeric-IgE alone is not able to trigger any changes on the overall protein-tyrosine phosphorylation patterns compared with resting cells; nor was it able to trigger calcium release from internal stores; neither degranulation. On the other hand FceRI-aggregation did indeed trigger all these responses (Fig. 6A,B \&6C).

\section{Discussion}

Binding of IgE to FceRI enhances the cell surface expression of FceRI, as a result, its ability to promote the stabilization/accumulation of FceRI on the mast cell surface in the presence of continued basal levels of protein synthesis $[32,33]$. It is possible that most of the enhanced $\operatorname{IgE}$ dependent functions that are observed after antigen or anti-IgE-induced Fc\&RI aggregation, in cells that have been sensitized with IgE, are a consequence of the higher level of Fc\&RI expression. However, a controversial question remains as to whether monomeric IgE can also have more direct effects on mast cell functions. Many studies over the years have shown no evidence that the binding of monomeric IgE can induce detectable signaling or production of mediators by mast cells. However, some groups have reported that monomeric IgE can enhance mast cell survival and trigger cytokine production $[24,28,33]$. In con- 

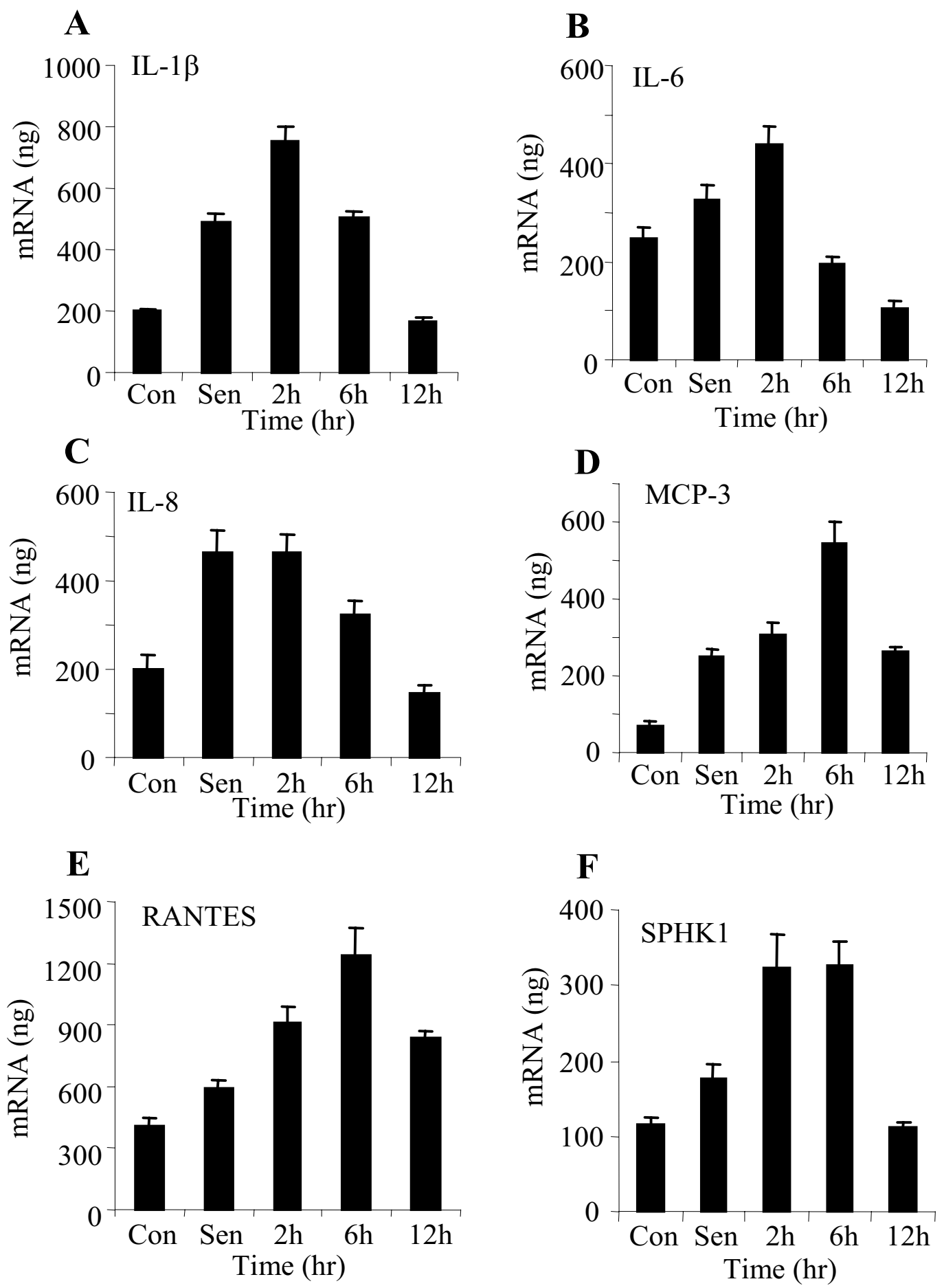

Figure 4

Real-Time PCR of selected genes. Comparison of gene expression from control/resting mast cells (Con); after mast cells were sensitized by human IgE (Sen), and following a time course of FceRI aggregation for 2 hours ( 2 h), 6 hours (6 h) and I 2 hours $(12 \mathrm{~h})$. I $\mu \mathrm{g}$ of total RNA was used from the same sample which has been used for microarray experiments at different time points for Light-Cycler Real-Time PCR. The concentrations of these transcripts were calculated using respective standard curves. (A) IL-I $\beta$ expression; (B) IL-6 expression; (C) IL-8 expression; (D) MCP3 expression; (E) RANTES expression; and (F) SPHKI expression. The data represent average \pm the standard deviation of four different samples. 
A

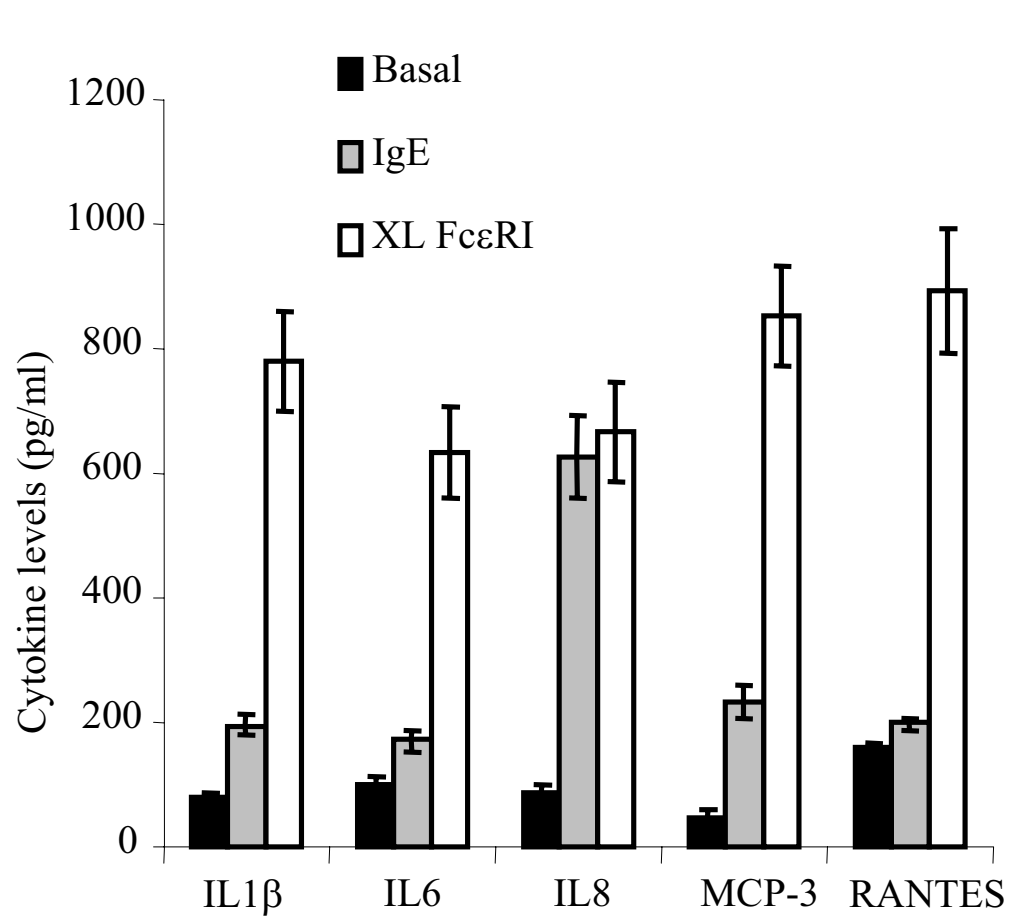

B

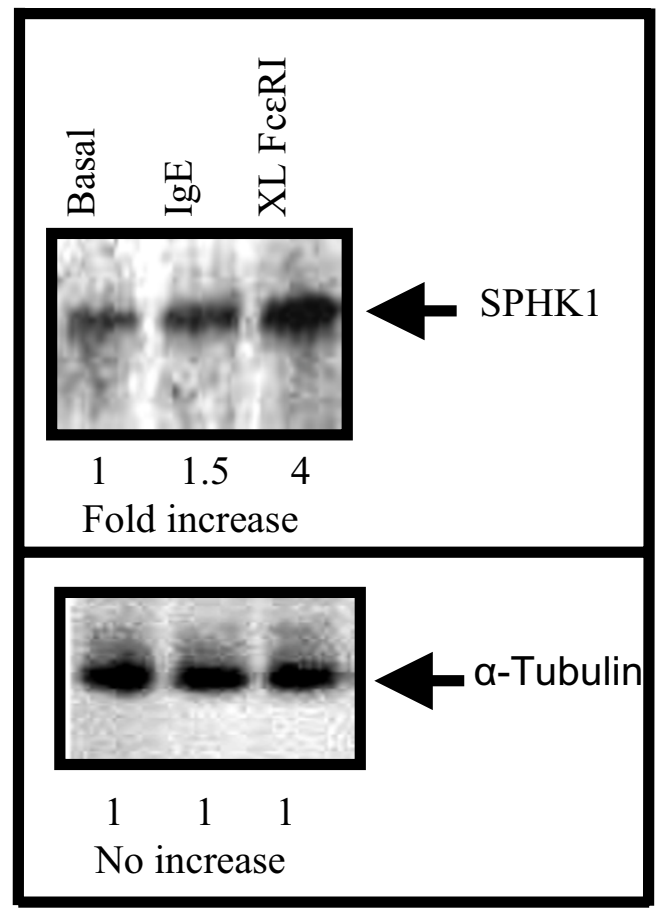

Figure 5

Protein expression analysis. A. ELISA for selected Cytokines and Chemokines. Cytokine and chemokine generation/release was determined from control-unstimulated mature mast cell (Basal); following lgE-sensitization (IgE) for 24 hours; and $\mathrm{Fc \varepsilon RI}$ aggregation by addition of the anti-human lgE to sensitized cells for 24 hours (XLFc\&RI). Cell culture supernatants were analyzed for bioactive IL-I $\beta$; IL-6; IL-8; MCP-3 and RANTES by ELISA. Results shown are the mean plus the standard deviation of triplicate measurements and are representative of four separate experiments. B. Western Blot analysis of SPHK I. Upper panel; differential expression of SPHKI was assessed by Western blot on lysates from control unstimulated cells (Basal); following lgE-sensitization (lgE) for 24 hours; and Fc\&RI aggregation by addition of the anti-human lgE to sensitized cells for 24 hours (XLFceRI). Lower panel; the blots were probed for $\alpha$-tubulin (control for equal loading). Results shown are representative of four separate experiments.

trast, a recent study by Matsuda et al [24], fail to find any ability of IgE to enhance mast cell survival on withdrawal of SCF. Interestingly, the study by Matsuda et al, also showed that IgE sensitization alone can induce the upregulation of cytokines and chemokines at the protein level, namely IL-8 and MCP1 [24]. In agreement to this, we show that IL-8 is induced by IgE alone at the mRNA as well as at the protein level (table 1, and Figures 4 and 5), in contrast we could not detect any significant increment on MCP-1 levels, we can speculate that this difference could be due to the different amounts IgE used $(1 \mu \mathrm{g} / \mathrm{mL}$ $v s 2.5 \mu \mathrm{g} / \mathrm{mL}$ ). However, we also show the upregulation of various chemokines, including the MCP-1-related protein MCP-3, which was also upregulated by IgE alone (table 1, and Figures 4 and 5). In our present study, we found that several genes related to proliferation were upregulated by IgE alone (Table 1); however, whether these genes, if fully transcribed, may be able to trigger mast cell proliferation in the absence of SCF is not known.

The observation that IgE alone can induce the upregulation of a substantial number of genes encoding for cytokines and chemokines, has profound implications in our understanding of the role of mast cell in inflammation. Cytokines and chemokines share many activities, including the ability to induce fever and shock syndrome in animal models [27]. Cytokine and chemokine production are universal components of a wide range of disease states, including immune-complex-mediated conditions such as nephritis [34], arthritis [35], and acute graft rejec- 
A

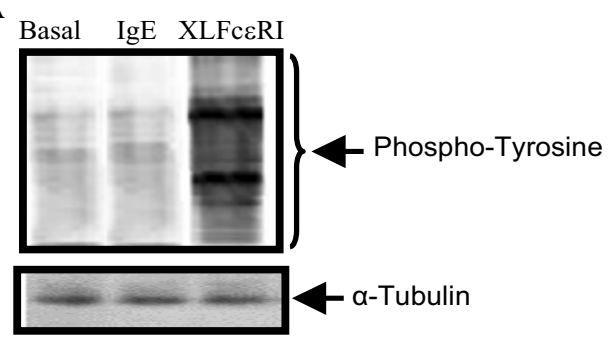

B

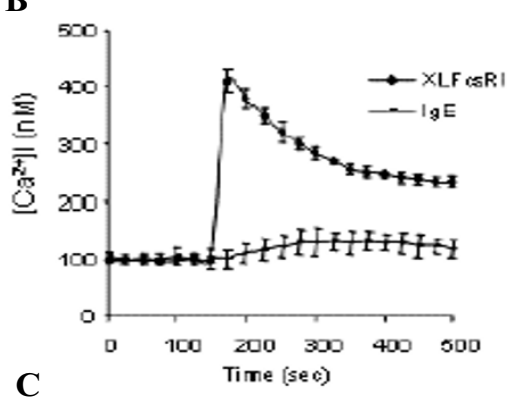

C

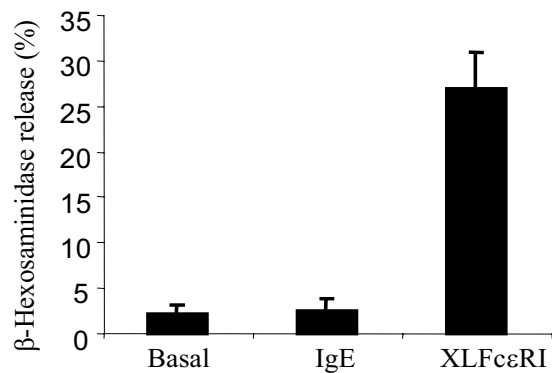

Figure 6

Mast cell activation: tyrosine phosphorylation, calcium signals, degranulation. A. Analysis of overall protein phosphorylation on tyrosine residues. Upper panel; overall tyrosine-phosphorylation pattern was analysed in cell extracts from: control unstimulated cells (Basal); cells treated with $\operatorname{lgE}$ alone for (IgE) for $5 \mathrm{~min}$; and after Fc\&RI crosllinking for $5 \mathrm{~min}$ (XLFcERI). Lower panel; the blots were probed for $\alpha$-tubulin (control for equal loading). Results shown are representative of four separate experiments. B. Levels of intracellular free calcium. Intracellular calcium measurements of mast cells following addition of $\mathrm{lgE}$ alone ( $\operatorname{lgE}$ ); and following the addition of the anti-human $\operatorname{lgE}$, to $\operatorname{lgE}$ sensitized cells (XLFceRI), the intracellular calcium levels were analyzed in a continuous reading for the timesstated in the graph. Results shown are the mean plus the standard deviation of triplicate measurements and are representative of four separate experiments. C. Degranulation. B-hexosaminidase release was determined from control-unstimulated mast cells (Basal); following monomeric-lgEsensitization for 30 minutes (lgE); and following FceRI aggregation by addition of the anti-human IgE to sensitized cells for 30 minutes (XLFc\&RI). Results shown are the mean plus the standard deviation of triplicate measurements and are representative of four separate experiments. tion [36]. These data suggest a potential role for mast cells in triggering, or at least contributing to, strong inflammatory responses.

In is also interesting to mention that, several genes encoding for transcription factors were upregulated by monomeric-IgE and FceRI aggregation. Perhaps the most prominent of these transcription factors, is NFKB. NFKB represents a family of related proteins which dimerize to form transactivating complexes [35]. NFkB dimmers are sequestered in the cytoplasm by interaction with inhibitory proteins (the IкBs). Various stimuli activate kinase signaling cascades that result in the phosphorylation and degradation of $\mathrm{I} \kappa \mathrm{B}$, thereby releasing NFKB to translocate to the nucleus, where it activates transcription of target genes. Many studies have emphasized the role of this transcription factor in regulating genes at critical points in immune-cell development and activation [37]. Many NFKB targets are antiapoptotic [38], which may explain the importance of the NFKB pathway in oncogenesis and resistance to chemotherapy $[39,40]$. During an immuneresponse several genes are triggered by the $\mathrm{NF \kappa B}$, these include genes coding for the various proinflammatory molecules, such as MIPs, IL-1 $\beta$, IL-6, IL-8, TNF $\alpha$, GRO $\alpha$ and other cytokines, chemokines and cell adhesion molecules ICAM, VCAM and selectins [41].

As immune cells progress through development and respond to antigenic challenge, they trigger signal transduction pathways that alter their cellular functions and the activity of transcription factors, changing their effector functions and their gene expression profiles. During mast cell activation, many signaling molecules are engaged in diverse responses, ranging from calcium release from internal stores, degranulation, the generation of lipidderived proinflammatory mediators and the production of cytokines and chemokines. In our study we observed that a substantial number of genes coding for intracellular signaling proteins were upregulated, by at least 2 -fold, during mast cell stimulation (Table. 1g). Interestingly, we observed a substantial upregulation of the mRNA for sphingosine kinase 1 (SPHK1), even by IgE alone, this upregulation was also confirmed at the protein level. Sphingosine kinases are novel enzymes that phosphorylate sphingosine (a membrane lipid), to generate the bioactive molecule sphingosine-1-phosphate (SPP), which is implicated in several inflammatory responses. We and others have previously reported that SPHK1 plays a critical role in the intracellular signaling pathways triggered by FceRI in mast cells [28,31], and coordinates several physiological responses triggered by activated mast cells. We showed that SPHK1 is involved in the calcium signals triggered by FceRI aggregation in human mast cells, as well as playing a critical role for mast cell degranulation [31]. Previously, we reported a pivotal role for 
SPHK1 in monocyte activation by the high-affinity IgG receptor $(\mathrm{Fc} \gamma \mathrm{RI})[42,43]$, showing that SPHK is key in triggering calcium release from internal stores, and the activation of the phagocyte NADPH oxidase. Moreover, very recently we demonstrated the role of SPHK1 in inflammatory responses triggered by the anaphylatoxin $\mathrm{C} 5 \mathrm{a}$ in human neutrophil and macrophages. These responses include: calcium signals, degranulation, cytokine production and chemotaxis triggered by C5a $[44,45]$. The observation that the gene encoding for SPHK1 is activated during IgE-sensitization of mast cells, coupled to the findings above may indicate a key role for SPHK1 in mast cell triggered responses.

The significance of this research supports the notion that, activation of mast cells appear to be linked to a wide range of pathologies, not only in allergies (as is widely recognized), but potentially in other inflammatory conditions. The method of global gene expression analysis using cDNA or oligo-DNA microarrays has proven to be a sensitive method to identify and define/redefine the molecular determinants of several human disorders, including cancer and autoimmune diseases, and has provided us with signatures of the immune response [41]. Using this technology, complemented with powerful analytical methods, we compared the gene expression profiles of human mast cells stimulated by IgE sensitization, and from a series of time points of Fc\&RI aggregation, with unstimulated/control human mast cells. Whether changes in gene expression, under these conditions, are representative of a pathological state is not currently known. It is also not known whether IgE/antigen and FceRI aggregation will trigger the same set of genes in an organism, where a number of events may be activating mast cells at the same time. However, taken together, our data brings us better insights into the molecular basis of mast cell activation, and provides meaningful information, regarding the mechanisms by which mast cell activation may contribute to the overall activation of the immune response, having clinical implication for improving not only allergic conditions but potentially other inflammatory diseases, where mast cells may play a role.

\section{Conclusion}

This study is an attempt to elucidate the molecular mechanisms which mast cells undergo during "priming" IgE sensitization and full activation by FceRI aggregation in a global perspective. In conclusion, our present study provides information that mast cells, by generating a broad range of cytokines and chemokines, may be a potent contributor of the immune response by recruiting and/or activating other immune-effector cells including the activation of lymphocytes that may, in turn, continue the spreading of the inflammatory response. Moreover, changes in the gene expression pattern of transcription factors, intracellular signaling molecules, and cytoskeletal remodeling and anti-apoptosis pathways occur, which would also contribute to the amplification of the inflammatory response. Mast cells are well established innate immune-effector cells, and there is mounting evidence to, at least, suggest that mast cells may contribute to the development of acquired immunity [46,47], whether in host defense or in allergic or autoimmune diseases. It will be pivotal to define in more detail whether and under which circumstances mast cells may influence the development and/or magnitude of acquired immune responses.

\section{Methods}

Unless specifically stated all materials and reagents were purchased from Sigma-Aldrich (Singapore).

\section{Cell culture}

Human umbilical cord blood (CB) samples were collected from normal full-term deliveries of informed individuals with formal consents, meeting the Universality Institutional Review Board guidelines, for research using human samples. CD34+ haematopoietic progenitor-cells were harvested using MACS cell isolation kit (Miltenyi Biotec), following the manufacturer's instructions.

The isolated CD34+ haematopoietic progenitor-cells were cultured for 5-6-weeks in the presence of $100 \mathrm{ng} / \mathrm{ml}$ of Stem Cell Factor (SCF Cat: 300-07, PeproTec, Rocky Hill, $\mathrm{NJ}$ ), and for the first week this was supplemented with 10 ng/ml of Interleukin-3 (IL-3 Cat: 200-03, PeproTec, Rocky Hill, NJ). Cells were shown to be differentiated by staining them for specific mast cell markers as follows: for mast cells chymase, with an anti-human chymase mAb (IgG1MAB1254, Chemicon, Temecula, CA), and FITC-conjugated secondary antibody (anti-mouse IgG-FITC, SigmaAldrich, Singapore); for c-Kit with anti-human c-Kit mouse monoclonal PE-conjugated (Cat. No. 555714; clone YB5.B8, BD Biosciences - Pharmigen, Singapore), isotype control anti-mouse IgE-PE (Cat. No. 555749; clone MOPC-21, BD Biosciences - Pharmigen, Singapore); and for FceRI cell-surface expression with antihuman FceRI polyclonal (Rabbit-IgG-ab31494; Abcam, Cambridge, UK) and FITC-conjugated secondary antibody (anti-rabbit IgG-FITC, Sigma-Aldrich, Singapore) also used as isotype control, and analyzed immediately using a Coulter Epics-Elite ESP Flow Cytometer (Beckman, Germany). Purity was estimated at $>97 \%$. The differentiated mast cells were plated in 6 well plates and allowed to rest for $24 \mathrm{hr}$.

\section{Mast cell stimulation and RNA extraction}

After differentiation, mast cells were plated in 6 well plates and allowed to rest for $24 \mathrm{hr}$. Cells in all wells, except the control well, were sensitized with human monomeric IgE 
( $1 \mu \mathrm{g} / \mathrm{ml}$, IgE, Cat: 30-AI05, Lot number A01071004, Fitzgerald, Concord, MA) overnight. FceRI aggregation was carried out by incubating the cells with monoclonal mouse-anti-human IgE $(1 \mu \mathrm{g} / \mathrm{ml}$, Anti-human-IgE, Cat: MCA2115, clone 4C3, Serotec, Oxford, UK) at $37^{\circ} \mathrm{C}$, for 2 $\mathrm{hr}, 6 \mathrm{hr}$ and $12 \mathrm{hr}$. RNA was extracted from all the samples using the Qiagen RNeasy mini kit (Qiagen, Valencia, CA). Integrity of RNA was checked by formamide gel electrophoresis; quantification of RNA was carried out by measuring the $\mathrm{A}_{260 \mathrm{~nm}}$.

\section{Labeling and hybridization}

Labeling and hybridization was carried out as previously described [46]. Briefly, $8 \mu \mathrm{g}$ of total RNA from each sample was used to synthesize double stranded cDNA using T7-(dT24) oligonucleotide primer and Superscript Reverse transcriptase (Invitrogen). The resultant cDNA was purified and $1 \mu \mathrm{g}$ of purified cDNA was labeled with biotin by transcription in vitro. The labeled cRNAs were, fragmented in the presence of metal ions and then hybridized to HG-Focus array (Affymetrix), following hybridization the gene chips were washed and stained after which the chips were scanned by Gene Array Scanner (Agilent technologies).

\section{Microarray data collection and analysis}

Data collection and analysis was carried out using MicroArray Suite 5.0 (MAS) (Affymetrix). The absolute data (signal intensity, detection call and detection P-value) were exported into GeneSpring v7.0 (Silicon Genetics, Redwood City, CA, USA) software for analysis by parametric test based on cross gene error model (PCGEM). The ANOVA approach has been used to find differentially expressed genes $(P<0.05)$. The Benjamini and Hochberg False Discovery Rate multiple testing correction was applied.

\section{Gene expression profile clustering}

Agglomerative average-linkage hierarchical clustering of the five different experimental were obtained for selected groups of genes with Gene Spring 7.0 software (Silicon Genetics, Redwood City, CA, USA) using standard correlation as similarity matrix.

\section{Real-time Quantitative PCR}

Real-PCR was performed, as previously described [46], using $1 \mu \mathrm{g}$ of total RNA from the same samples used for microarray experiments. PCR was performed for transcripts of IL- $1 \beta$ (Primers: forward 5'-ATG GCA GAA GTA CCT AAG CTC GC-3', reverse 5'-ACA CAA ATT GCA TGG TGA AGT CAG TT-3'); IL-6 (Primers: forward 5'-ATG AAC TCC TTC TCC ACA AGC GC-3', reverse 5' GAA GAG CCC TCA GGC TGG ACT G-3'); IL-8 (Primers: forward 5'-ATG ACT TCC AAG CTG GCC GTG GCT-3', reverse 5'TCT CAG CCC TCT TCA AAA ACT TCT C-3'); MCP-3 (Primers: for- ward 5'-TCC AAG GCT TTA TGT TCA AA-3', reverse 5'ACT GAA CTG AAA ACA AGC CA-3'); RANTES (Primers: forward 5'-GCT GTC ATC CTC ATT GCT ACT G-3', reverse 5'-TCG AAC TCC TGA CCT CAA GTG ATC-3'); and for SPHK1 (Primers: forward 5'-TGA ACC CGC GCG GCA AGG GC-3', reverse 5'-GGT CAG CCG GCG CCA TCC ACG-3').

For amplicon detection, the Light Cycler RNA Master SYBR Green Kit (Roche) was used as described by the manufacturer. PCRs were performed in a LightCycler ${ }^{\circledR}$ instrument (Roche) as follows: reverse transcription at $61^{\circ} \mathrm{C}$ for $20 \mathrm{~min}$, initial denaturation at $95^{\circ} \mathrm{C}$ for $2 \mathrm{~min}$; amplification for $45-65$ cycles of denaturation $\left(95^{\circ} \mathrm{C}, 5 \mathrm{~s}\right.$, ramp rate $20^{\circ} \mathrm{C} / \mathrm{s}$ ), annealing (optimal temperature, $5 \mathrm{~s}$, ramp rate $20^{\circ} \mathrm{C} / \mathrm{s}$ ) and extension $\left(72^{\circ} \mathrm{C}\right.$, product length [bp] $/ 25 \mathrm{~s}$, ramp rate $2^{\circ} \mathrm{C} / \mathrm{s}$ ). A single online fluorescence reading for each sample was taken at the end of extension step. Quantitative results were expressed by identification of the second derivative maximum points, which marked the cycles where the second derivatives of the fluorescence signal curves are at maximum. These points were expressed as fractional cycle numbers. Then, these cycle numbers were plotted against the logarithm of the concentrations of serially 2-fold diluted standard samples to obtain a standard curve. The concentrations of unknown samples were calculated by extrapolation from this standard curve. Positive sample specificity was confirmed by determining the melting curve $\left(95^{\circ} \mathrm{C}, 5 \mathrm{~s}\right.$, ramp rate $20^{\circ} \mathrm{C} /$ $\mathrm{s}$; $68^{\circ} \mathrm{C}, 15 \mathrm{~s}$, ramp rate $20^{\circ} \mathrm{C} / \mathrm{s} ; 95^{\circ} \mathrm{C}$, 0 s, ramp rate $0.1^{\circ} \mathrm{C} / \mathrm{s}$, continuous measurement).

\section{Cytokine detection}

Supernatants from control cells, cells sensitized, and cells following FceRI aggregation, were collected and stored at -20C until use. IL-1 $\beta$, IL-6, IL-8, MCP-3 and RANTES levels in the supernatants were evaluated using ELISA (R\&D Systems Inc., MN, USA) following the manufacturer's instructions.

\section{Gel electrophoresis and Western blots}

Western blots were carried out as previously done [31]. Briefly, $40 \mu \mathrm{g}$ of lysate for each sample was resolved on $10 \%$ polyacrylamide gels (SDS-PAGE) under denaturing conditions and then transferred to $0.45 \mu \mathrm{m}$ nitrocellulose membranes.

For overall tyrosine phosphorytaion, the blots were probed using a specific monoclonal anti-phosphotyrosine primary antibody (P-Tyr, Sc-7020, Santa Cruz, CA, USA), and an anti-mouse HRP-conjugated secondary antibody (anti-mouse IgG-HRP, A-4416, Sigma). Bands were visualized using the ECL Western Blotting Detection System (Amersham, Singapore). 
For SPHK1 expression, the blots were probed using a rabbit polyclonal anti-SPHK1 primary antibody (antiSPHK1, X1627P, Exalpha, MA, USA), and HRP-conjugated secondary antibody (anti-rabbit IgG-HRP, sc-2004, Santa Cruz, CA, USA). For loading control the blots were probed with a monoclonal anti $\alpha$-tubulin (anti- $\alpha$-tubulin, sc-5286, Santa Cruz, CA, USA), and an anti-mouse HRPconjugated secondary antibody (anti-mouse IgG-HRP, A4416, Sigma). Bands were visualized using the ECL Western Blotting Detection System (Amersham, Singapore), and quantified by densitometry analysis.

\section{Cytosolic $\mathrm{Ca}^{2+}$}

Cytosolic calcium was measured as described previously [31]. Briefly, cells were loaded with $1 \mu \mathrm{g} / \mathrm{ml}$ Fura2-AM (Molecular Probes, Leiden, The Netherlands) in PBS, 1.5 $\mathrm{mM} \mathrm{Ca}^{2+}$ and $1 \%$ BSA. After removal of excess reagents by dilution and centrifugation (in PBS), the cells were resuspended in PBS containing $1.5 \mathrm{mM} \mathrm{Ca}^{2+}$ and $1 \% \mathrm{BSA}$, for $30 \mathrm{~min}$; or in PBS containing $1.5 \mathrm{mM} \mathrm{Ca}^{2+}, 1 \% \mathrm{BSA}$, and human-monomeric IgE $(1 \mu \mathrm{g} / \mathrm{ml})$ for sensitization, for 30 min. After removal of excess IgE by dilution and centrifugation (in PBS), the cells were resuspended in $1.5 \mathrm{mM}$ $\mathrm{Ca}^{2+}$ supplemented PBS and warmed to $37^{\circ} \mathrm{C}$ in the cuvette; Unsensitazed cells were placed in the cuvette and cytosolic calcium was measured before and after the addition of monomeric IgE. IgE-sensitized cells were placed in the cuvette and FcERI was crosslinked by addition of mouse-anti-human IgE $(1 \mu \mathrm{g} / \mathrm{ml})$. Fluorescence was measured at 340 and $380 \mathrm{~nm}$.

\section{$\beta$-hexosaminidase release}

Degranulation was measured using as previously described [31]. Briefly, an aliquot of cells was resuspended in PBS containing $1.5 \mathrm{mM} \mathrm{Ca}^{2+}$ and $1 \%$ BSA, and incubated with monomeric $\operatorname{IgE}$ for $30 \mathrm{~min}$ at $37^{\circ} \mathrm{C}$. Another aliquot of cells was resuspended in PBS containing human-monomeric IgE $(1 \mu \mathrm{g} / \mathrm{ml})$ for sensitization, $1.5 \mathrm{mM} \mathrm{Ca}^{2+}$ and $1 \% \mathrm{BSA}$, for $30 \mathrm{~min}$. After removal of excess IgE by dilution and centrifugation (in PBS), the cells were resuspended in $1.5 \mathrm{mM} \mathrm{Ca}^{2+}$ supplemented PBS, and FcERI was crosslinked by addition of mouseanti-human IgE $(1 \mu \mathrm{g} / \mathrm{ml})$ to cells for $30 \mathrm{~min}$ at $37^{\circ} \mathrm{C}$.

Following the incubation, $50 \mu \mathrm{l}$ of supernatant, was incubated with $200 \mu \mathrm{l}$ of $1 \mathrm{mM} p$-nitrophenyl $N$-acetyl- $\beta$-Dglucosaminide for $1 \mathrm{hr}$ at $37^{\circ} \mathrm{C}$. The total $\beta$-hexosaminidase concentration was determined by a 1:1 extraction of the remaining buffer and cells with 1\% Triton X-100; a 50 $\mu \mathrm{l}$ aliquot was removed and analyzed as described. Reactions were quenched by addition of $500 \mu \mathrm{l}$ of $0.1 \mathrm{M}$ sodium carbonate buffer. The enzyme concentration was determined by measuring the OD at $400 \mathrm{~nm}$. $\beta$-hexosaminidase release was represented as a percent of total enzyme.

\section{Flow cytometry analysis for mast cell markers}

To analyze the expression of the intracellular mast cell chymase, $1 \times 10^{6}$ cells were washed with ice cold PBS, fixed and permeabilised using the FIX and PERM reagents from Caltag (Caltag Laboratories, Burlingame, CA) as follows: after washing, samples were resuspended in $100 \mathrm{ul}$ of Reagent A (Fixation medium) and incubated for $15 \mathrm{~min}$ at RT. The cells were then washed twice with ice-cold PBS, and resuspended in $100 \mathrm{ul}$ of Reagent B (Permeabilization medium) and incubated for $15 \mathrm{~min}$ at RT. Cells were washed twice and resuspended in $100 \mu \mathrm{l}$ of PBS/1\% FBS and $5 \mu \mathrm{l}$ of the anti-human chymase mAb (IgG1MAB1254, Chemicon, Temecula, CA) was added and samples were incubated for $20 \mathrm{~min}$ at RT. Samples were washed twice in ice-cold PBS, then resuspended in PBS/ $1 \%$ FBS and $5 \mu \mathrm{l}$ of FITC-conjugated secondary antibody (anti-mouse IgG-FITC, Sigma-Aldrich, Singapore) was added, and incubated in dark for an $30 \mathrm{~min}$ at RT. Samples were washed twice with ice-cold PBS and resuspended in $100 \mu \mathrm{l}$ of PBS/1\% FBS for immediate analysis.

To analyze the cell surface expression of cKit and FceRI, the samples were initially processed as above except that the permeabilisation step was omitted. For c-Kit the primary antibody was an anti-human c-Kit mouse monoclonal (MCA1841, clone 104D2, Serotec, Oxford, UK), and the secondary antibody was a FITC-conjugated (antimouse IgG-FITC, Sigma-Aldrich, Singapore). For FcERI cell-surface expression, the cells were labeled with the primary anti-human FceRI polyclonal (Rabbit-IgG-ab31494. Abcam, Cambridge, UK), and the secondary antibody was a FITC-conjugated (anti-rabbit IgG-FITC, Sigma-Aldrich, Singapore). All the samples were analyzed by flow cytometry was using a FACSCalibur machine (BD biosciences), and the data analysed using the Cell Quest ${ }^{\mathrm{TM}}$ Pro Software.

\section{Authors' contributions}

MJ carried out data analysis and prepared the microarraydata table and figures. HKT isolated the progenitor cells, differentiated the Mast cells and carried out the receptor crosslinking. RR carried out the RNA extraction, labeling and microarray hybridization. LZ carried out RT-PCR. KKC and MR provided the cord blood. AJM designed the study and drafted the manuscript. All authors read and approved the final manuscript.

\section{Acknowledgements}

This work was supported by a BMRC-Young Investigator Award (R-185000-044-305). We thank A-K Fraser-Andrews for proofreading the manuscript.

\section{References}

I. Mekori YA, Metcalfe DD: Mast cells in innate immunity. Immunol Rev 2000, 73:131-140.

2. Galli SJ, Nakae S: Mast cells to the defense. Nature Immunology 2004, 4: I I60-1 I 62. 
3. Benoist C, Mathis D: Mast cells in autoimmune disease. Nature 2002, 420:875-878.

4. Metcalfe DD, Baram D, Mekori YA: Mast cells. Physiol Rev 1997, 77:1033-1079.

5. Williams CM, Galli SJ: The diverse potential effector and immunoregulatory roles of mast cells in allergic disease. J Allergy Clin Immunol 2000, I 05:847-859.

6. Sayama K, Diehn M, Matsuda K, Lunderius C, Tsai M, Tam SY, Botstein D, Brown PO, Galli S): Transcriptional response of human mast cells stimulated via the Fc\&RI and identification of mast cells as a source of IL-I I. BMC Immunol 2002, 3:5.

7. Metzger $\mathrm{H}$ : The receptor with high affinity for IgE. Immunol Rev 1992, I 25:37-48.

8. Turner $\mathrm{H}$, Kinet JP: Signalling through the high-affinity IgE receptor Fc\&RI. Nature 1999, 402:24-30.

9. Wedemeyer J, Tsai M, Galli SJ: Roles of mast cells and basophils in innate and acquired immunity. Curr Opin Immunol 2000 , | 2:624-631.

10. Galli SJ: Complexity and redundancy in the pathogenesis of asthma: reassessing the roles of mast cells and $\mathbf{T}$ cells. J Exp Med 1997, 1 86:343-347.

II. Williams CM, Galli SJ: Mast cells can amplify airway reactivity and features of chronic inflammation in an asthma model in mice. J Exp Med 2000, 192:455-462

12. Kobayashi T, Miura T, Haba T, Sato M, Serizawa I, Nagai H, Ishizaka $\mathrm{K}$ : An essential role of mast cells in the development of air way hyperresponsiveness in a murine asthma model. J Immunol 2000, I 64:3855-386I.

13. Malaviya R, Ross EA, MacGregor JI, Ikeda T, Little JR, Jakschik BA, Abraham SN: Mast cells phagocytosis of FimH expressing enterobacteria. J Immunol | 994, I 52:1907-19|4.

14. Marone G, Gentile M, Petraroli A, De Rosa N, Triggiani M: Histamine-induced activation of human lung macrophages. Int Arch Allergy Immunol 200I, I 24:249-252.

I5. McLachlan JB, Hart JP, Pizzo SV, Shelburne CP, Staats HF, Gunn MD, Abraham SN: Mast cell-derived tumor necrosis factor induces hypertrophy of draining lymph nodes during infection. Nat Immunol 2003, 4: I I99-1205

16. Saito H, Nakajima T, Matsumoto K: Human mast cell transcriptome project. Int Arch Allergy Immunol 200I, I 25: I-8.

17. Kuramasu A, Kubota Y, Matsumoto K, Nakajima T, Sun XM, Watanabe $T$, Saito $H$, Ohtsu $H$ : Identification of novel mast cell genes by serial analysis of gene expression in cord blood-derived mast cells. FEBS Lett 200I, 498:37-4I

18. Nakajima T, Matsumoto $\mathrm{K}$, Suto $\mathrm{H}$, Tanaka $\mathrm{K}$, Ebisawa M, Tomita $\mathrm{H}$, Yuki K, Katsunuma T, Akasawa A, Hashida R, Sugita Y, Ogawa H, Ra $C$, Saito $H$ : Gene expression screening of human mast cells and eosinophils using high-density oligonucleotide probe arrays: abundant expression of major basic protein in mast cells. Blood 200I, 98: I I27-II34.

19. Babina M, Guhl S, Starke A, Kirchhof L, Zuberbier T, Henz BM: Comparative cytokine profile of human skin mast cells from two compartments strong resemblance with monocytes at baseline but induction of IL-5 by IL-4 priming. J Leukoc Biol 2004 75:244-252.

20. Nakamura $R$, Ishida $S$, Ozawa $S$, Saito $Y$, Okunuki $H$, Teshima $R$, Sawada J: Gene expression profiling of $\mathrm{Ca}^{2+}$-atapase inhibitor DTBHQ and antigen-stimulated RBL-2H3 mast cells. Inflamm Res 2000, 5 I:6II-6I8.

21. Okumura S, Kashiwakura J, Tomita H, Matsumoto K, Nakajima T, Saito $\mathrm{H}$, Okayama $\mathrm{Y}$ : Identification of specific gene expression profiles in human mast cells mediated by Toll-like receptor 4 and FcERI. Blood 2003, I 02:2547-2554.

22. Wakahara S, Fujii $Y$, Nakao T, Tsuritani K, Hara T, Saito $H$, Ra C: Gene expression profiles for Fc\&RI, cytokines and chemokines upon FceRI activation in human cultured mast cells derived from peripheral blood. Cytokine 2000, 16:143-I52.

23. Nakajima T, Inagaki N, Tanaka $H$, Tanaka A, Yoshikawa $M$, Tamari $M$, Hasegawa K, Matsumoto K, Tachimoto H, Ebisawa M, Tsujimoto G Matsuda $\mathrm{H}$, Nagai $\mathrm{H}$, Saito $\mathrm{H}$ : Marked increase in $\mathbf{C C}$ chemokine gene expression in both human and mouse mast cell transcriptomes following Fc\&-receptor I cross-linking: an interspecies comparison. Blood 2002, I 00:386I-3868.

24. Matsuda K, Piliponsky M, likura M, Nakae S, Wang EW, Dutta SM, Kawakami T, Tsai M, Galli S]: Monomeric IgE enhances human mast cell chemokine production: IL-4 augments and dexam- ethasone suppresses the response. I Allergy Clin Immunol 2005 I 16:1357-1363.

25. NCBIs Gene Expression Omnibus [http:// www.ncbi.nlm.nih.gov/geo/]

26. Gene Ontology Consortium [http://www.geneontology.org/]

27. Okusawa S, Gelfand JA, Ikejima T, Connolly RJ, Dinarello CA: Interleukin- I induces a shock-like state in rabbits: Synergism with tumor necrosis factor and the effects of cyclooxygenase inhibition. J Clin Invest 1998, 8 I: I |62-I |72.

28. Kalesnikoff J, Huber M, Lam V, Damen JE, Zhang J, Siraganian RP, Krystal G: Monomeric IgE Stimulates Signaling Pathways in Mast Cells that Lead to Cytokine Production and Cell Survival. Immunity 200I, I4:80I-8II.

29. Ghosh S, May MJ, Kopp EB: NF-kappa B and Rel proteins: evolutionary conserved mediators of immune responses. Annu Rev Immunol 1998, 1 6:225-260.

30. Crabtree GR: Generic signals and specific outcomes: signaling through $\mathrm{Ca}^{2+}$, calcineurin, and NF-AT. Cell |999, 96:6||-6|4

31. Melendez AJ, Khaw AK: Dichotomy of $\mathbf{C a}^{2+}$ Signals Triggered by Different Phospholipid Pathways in Antigen Stimulation of Human Mast Cells. J Biol Chem 2002, 277:I7255-I7262.

32. Borkowski TA, Jouvin MH, Lin SY, Kinet JP: Minimal requirements for IgE mediated regulation of surface Fc\&RI. J Immunol 200I, 167:1290-1296.

33. Kubo S, Matsuoka K, Taya C, Kitamura F, Takai T, Yonekawa H, Karasuyama $\mathrm{H}$ : Drastic up-regulation of Fc\&RI on mast cells is induced by IgE binding through stabilization and accumulation of FCERI on the cell surface. J Immunol 200 I, I 67:3427-3434

34. Matsumoto $\mathrm{K}$, Kanmatsuse $\mathrm{K}$ : Increased IL- $\mathbf{2}$ release by monocytes in nephritic patients. Clin Exp Immunol 1999, I I 7:36 I-367.

35. DeVries ME, Ran L, Kelvin DJ: The physiological and pathophysiological role of chemokines during inflammatory and immunological responses. Semin Immunol 1999, I I:95-104.

36. Hill GR, Teshima T, Gerbitz A, Pan L, Cooke KR, Brinson YS, Crawford JM, Ferrara JL: Differential roles of IL-I and TNF- $\alpha$ on graft versushost disease and graft versus leukemia. J Clin Invest 1999. I 04:459-467.

37. Gugasyan R, Grumont R, Grossmann M, Nakamura Y, Pohl T, Nesic $D$, Gerondakis S: Rel/NF- $\kappa$ B transcription factors: key mediators of B-cell activation. Immunol Rev 2000, I 76: I 34-I 40.

38. Hinz M, Loser P, Mathas S, Krappmann D, Dorken B, Scheidereit C: Constitutive $N_{F} \in$ maintains high expression of a characteristic gene network, including CD40, CD86, and a set of antiapoptotic genes in Hodgkin/Reed-Stemberg cells. Blood 200I, 97:2798-2807.

39. Baldwin AS: Control of oncogenesis and cancer therapy resistance by the transcription factor NF- $\kappa$ B. J Clin Invest 200I, I 07:24l-246.

40. Choi $\mathrm{OH}, \mathrm{Kim} \mathrm{JH}$, Kinet J-P: Calcium mobilization via sphingosine kinase in signalling by the Fc\&RI antigen receptor. Nature 1996, 18:634-646.

4I. Shaffer AL, Rosenwald A, Hurt EM, Giltnane JM, Lam LT, Pickeral OK, Staudt LM: Signatures of the immune response. Immunity 200 I, I 5:375-385.

42. Melendez A, Floto RA, Gillooly DJ, Harnett MM, Allen JM: Fc $\gamma \mathbf{R I}$ Coupling to Phospholipase D Initiates Sphingosine Kinasemediated Calcium Mobilization and Vesicular Trafficking. J Biol Chem 1998, 273:9393-9402.

43. Melendez A, Floto RA, Cameron AJ, Gillooly DJ, Harnett MM, Allen JM: A molecular switch changes the signalling pathway used by the Fc $\gamma \mathbf{R I}$ antibody receptor to mobilize calcium. Curr Biol |998, 8:210-221.

44. Ibrahim FB, Pang SJ, Melendez AJ: Anaphylatoxin signaling in human neutrophils: A key role for sphingosine kinase. J Biol Chem 2004, 279:44802-448II.

45. Melendez AJ, Ibrahim FB: Antisense knockdown of Sphingosine kinase $I$ in human macrophages inhibits $\mathbf{C 5 a}$ receptordependent signal transduction, $\mathrm{Ca}^{2+}$ signals, enzyme release, cytokine production and chemotaxis. I Immunol 2004, I 73:| 596-603.

46. Galli SJ, Nakae S, Tsai M: Mast cells in the development of adaptive immune responses. Nature Immunology 2005, 6:35-I 42.

47. Gregory GD, Brown MA: Mast cells in allergy and autoimmunity: implications for adaptive immunity. Methods $\mathrm{Mol}$ Biol 2006, 3 I 5:35-50. 
48. Reghunathan R, Jayapal M, Hsu LY, Chng HH, Tai D, Leung BP, Melendez AJ: Expression profile of immune response genes in patients with Severe Acute Respiratory Syndrome. BMC Immunol 2005, 6:2.

Publish with Bio Med Central and every scientist can read your work free of charge

"BioMed Central will be the most significant development for disseminating the results of biomedical research in our lifetime. " Sir Paul Nurse, Cancer Research UK

Your research papers will be:

- available free of charge to the entire biomedical community

- peer reviewed and published immediately upon acceptance

- cited in PubMed and archived on PubMed Central

- yours - you keep the copyright

Submit your manuscript here:

http://www.biomedcentral.com/info/publishing_adv.asp
BioMedcentral 